\title{
Erratum to: The deep-water squid Octopoteuthis sicula Rüppell, 1844 (Cephalopoda: Octopoteuthidae) as the single species of the genus occurring in the Mediterranean Sea
}

\author{
Patrizia Jereb $^{1} \cdot$ Rita Cannas $^{2} \cdot$ Porzia Maiorano $^{3}$ - Giambattista Bello ${ }^{4}$ Fulvio Garibaldi ${ }^{5}$ Marco Mereu $^{2}$. \\ Francesco G. Ancona ${ }^{3}$ - Giovanni Ammendolia ${ }^{6}$ • Pietro Battaglia ${ }^{7}$ • Önder Duysak ${ }^{8}$ - Hendrik Jan T. Hoving9 ${ }^{9}$ \\ Eugenia Lefkaditou ${ }^{10} \cdot$ Marek R. Lipinski $^{11} \cdot$ Riccardo Melis $^{2} \cdot$ Panagiota N. Peristeraki $^{12} \cdot$ Sergio Ragonese $^{13}$. \\ Teresa Romeo $^{7}$ - Alp Salman ${ }^{14} \cdot$ Maria Begoña Santos ${ }^{15} \cdot$ Alberto Villari $^{16} \cdot$ Danila Cuccu $^{2}$ (i)
}

(C) Springer-Verlag Berlin Heidelberg 2016

\section{Erratum to: Mar Biol (2016) 163:192 \\ DOI 10.1007/s00227-016-2965-0}

Unfortunately, the name of the author "Maria Begoña Santos" was incorrectly published in the original version, which is corrected in this erratum.

The online version of the original article can be found under doi:10.1007/s00227-016-2965-0.

Danila Cuccu

cuccu@unica.it

1 Italian National Institute for Environmental Protection and Research, via V. Brancati 48/60, 00144 Rome, Italy

2 Department of Life Science and Environment, University of Cagliari, via T. Fiorelli 1, 09126 Cagliari, Italy

3 Department of Biology, University of Bari Aldo Moro, via Orabona 4, 70125 Bari, Italy

4 Arion, via Colombo 34, 70042 Mola di Bari, Italy

5 Laboratorio di Biologia Marina ed Ecologia Animale Dip.te.Ris., University of Genova, Corso Europa 26, 16132 Genoa, Italy

6 Cooperativa Sicilianella, via Consolare Pompea 3, 98168 Messina, Italy

7 Italian National Institute for Environmental Protection and Research, Laboratory of Milazzo (ME), via dei Mille 46, 98057 Milazzo, Italy

8 Faculty of Fisheries, University of Mustafa Kemal, 31200 Iskenderun, Hatay, Turkey
9 GEOMAR, Helmholtz Centre for Ocean Research, Kiel, Düsternbrooker Weg 20, 24105 Kiel, Germany

10 Hellenic Centre for Marine Research, Institute of Marine Biological Resources, Ag Kosmas, Helliniko, 16777 Athens, Greece

11 Department of Ichthyology and Fisheries Science, Rhodes University, P.O. Box 94, Grahamstown 6140, South Africa

12 Hellenic Centre for Marine Research, Institute of Marine Biological Resources, 71500 Gournes Pediados Crete, Greece

13 National Research Council, Institute for the Coastal Marine Environment, via Luigi Vaccara 61, 91026 Mazara del Vallo, Trapani, Italy

14 Department of Hydrobiology, Faculty of Fisheries, Ege University, 35100 Bornova, Izmir, Turkey

15 Instituto Español de Oceanografía, Centro Oceanográfi co de Vigo, Subida a Radio Faro, 50, 36390 Vigo, Pontevedra, Spain

16 Via Villa Contino 30, 98124 Messina, Italy 